\title{
EL SEMINARIO EN LA «RATIO FUNDAMENTALIS»
}

DOI: https://doi.org/10.52039/seminarios.v63i219.90

JosÉ ANTONIO SANZ AROZARENA*

Como no podía ser de otra manera, el seminario es un tema central en El don de la vocación presbiteral. Ratio Fundamentalis Institutionis Sacerdotalis (2016).

En las páginas siguientes trataré sobre todo de subrayar algunos puntos clave del documento; sólo en un segundo momento reflexionaré y concretaré varios aspectos desde la realidad del seminario estadounidense donde trabajo. Invito a cada lector a realizar este mismo ejercicio a partir de su contexto diocesano propio.

\section{Apuntes para una lectura de la Ratio}

La estructura de la Ratio es clara: La Introducción narra los pasos que se dieron para producir este documento. 1) Normas generales, dirigidas a quienes deben adaptar e implementar la Ratio. 2) Las vocaciones sacerdotales, describe los distintos tipos de personas que se presentan como candidatos al presbiterado, dedicando un apartado específico a los seminarios menores. 3) Los fundamentos de la formación, pone las bases sobre las que se ha de elaborar el proceso formativo. 4) La formación inicial y permanente, describe las etapas del proceso formativo. 5) Las dimensiones de la formación, actualiza los «cuatro pilares» descritos en Pastores dabo vobis (PDV) de Juan Pablo II. 6) Los agentes de la formación, abarca tanto a los formadores del seminario, como al obispo y a la comunidad. 7) Organización de los estudios de filosofía y teología, a los que se les añade otras «materias ministeriales». 8) Criterios y normas, trata aspectos específicos sobre la admisión y expulsión de candidatos, así como de otros asuntos de tipo jurídico.

* José Antonio Sanz Arozarena es Rector del Seminario BI. Junípero Serra House of Formation, en Estados Unidos. Pertenece a la Hermandad de Sacerdotes Operarios Diocesanos. 


\section{Preocupaciones}

La Ratio, como otros documentos eclesiales, pretende corregir una práctica que se considera, de alguna manera, deficiente. Por lo tanto, hay que empezar por preguntarse ¿qué preocupa a los responsables de la Iglesia en este ámbito?

Me parece que son varias las preocupaciones que subyacen a lo largo de la Ratio y que afloran de vez en cuando en el texto. Las he agrupado un tanto artificialmente bajo tres títulos.

\section{a) Formación / Configuración}

La palabra más repetida en la Ratio tal vez sea «formación», entendida como formación humana y configuración con Cristo Cabeza, Pastor, Siervo y Esposo (35-40).

Se dice que la meta de la formación es la conformación del corazón del seminarista al Corazón de Cristo $(89,111,115)$. Una vez ordenado, «es necesario que cada sacerdote se sienta siempre un discípulo en camino, necesitado constantemente de una formación integral, entendida como una continua configuración con Cristo» (Introducción 3). «El presbítero, por tanto, debe ser formado de modo que su corazón y su vida sean conformes al Señor Jesús, llegando a ser un signo del amor de Dios para cada hombre» (40 y 42$)$.

La configuración con Cristo continúa a lo largo de toda la vida, de ahí la necesidad de una formación permanente (80).

La Ratio se mueve en esta dirección porque está preocupada por:

-la dispersión, fragmentación, parcialidad o polarización $(28,153,159$, 165, 186): parece ser que se les hace difícil a los seminaristas integrar en un todo las distintas partes en que se desarrolla la formación en el seminario $(53,89-94,142)$. Por tanto, la labor formativa les ha de ayudar a integrar su humanidad «en un camino de fe y de progresiva y armónica maduración de todos los componentes» (28 y 43), «realizando una síntesis interior» (29); de ahí que la Ratio caracterice la formación como «única, integral, comunitaria y misionera» (3);

-la superficialidad (28): el seminarista puede «pasar» por el seminario durante varios años sin interiorizar actitudes, es decir sin haber adquirido la «forma» de Cristo $(58,92,131)$. Sin embargo, no le es permitido al presbítero quedarse a un nivel de "apariencia» y exterioridad $(41,42)$. Por tanto, el «anhelo de 'configurarse' con Cristo» dura toda la vida, aunque se ponga mayor atención en unas etapas que en otras (57). 


\section{b) Bautismo / Orden}

El bautismo es el sacramento básico para cualquier cristiano; es la puerta de entrada a todo desarrollo posterior. El sacramento del orden no «des-bautiza», sino que continúa el camino de discipulado iniciado en el bautismo $(3,12)$. «La unidad y la dignidad de la vocación bautismal preceden cualquier diferencia ministerial» (31). Hay un único discipulado. Este es el punto de partida del «discípulo misionero», que desarrolla el sacramento del orden. «El sacerdote proviene de la comunidad cristiana y a ella regresa para servirla y guiarla en calidad de pastor» (3). El presbítero proviene «de» una comunidad y ejerce su ministerio «en» una comunidad y «para» la comunidad (32). El ministerio presbiteral es un «servicio a la gloria de Dios y al sacerdocio bautismal de los hermanos» (31).

Las dos preocupaciones que se tratan bajo esta perspectiva son:

-clericalismo (33): pensar que uno pertenece a una clase especial dentro de la Iglesia y que merece gozar de unos privilegios particulares, con la tentación de «dominar a los que les han sido encomendados» (34);

-protagonismo $(41,120)$, individualismo $(42,52,63,87,175)$ : trabajar por su propia cuenta, aislado de los demás, con la pretensión de imponerse a la comunidad en lugar de buscar la colaboración de otros, que ha de incluir a los laicos $(119,150$, y en especial a las mujeres, 95,151$)$.

\section{c) Paternidad / Fraternidad}

El presbítero es «padre espiritual» en relación a los otros miembros de la comunidad (33) y «hermano» en relación a otros presbíteros (aunque a veces la Ratio aplica también la palabra «hermano» a todos los bautizados), creando una «fraternidad sacramental» $(51,82,87,88,90)$. Los formadores en el seminario son «padres espirituales» de los seminaristas; los seminaristas, por su parte, deben desarrollar un sentido de fraternidad entre ellos mismos (52).

Detrás de esta indicación está la preocupación por:

-carrerismo (84): apego a una posición, ansia de poder y deseo de riqueza; el ministerio como un medio para ganarse la vida; el considerarse empleado de una empresa; un afán por promociones, una búsqueda de reconocimientos;

-funcionario de lo sagrado (84): verse como un técnico que provee ciertos servicios, «un profesional del Espíritu» (120, cita del Papa Francisco).

En resumen, la Ratio tiene dos grandes preocupaciones: falta de interioridad y relaciones deficientes. 


\section{La pregunta}

Las preocupaciones nos llevan a formular una pregunta, ya que toda afirmación presupone una pregunta. Podemos formularla así: ¿Cómo formamos discípulos misioneros que presidan el pueblo de Dios para servir en un hospital de campaña en medio de un mundo deshumanizante? La Ratio recuerda que el seminario hace madurar «la conformación con Cristo, que se hace próximo a todos los hombres, incluso a los más lejanos» como el buen samaritano que venda heridas (99, cita del Papa Francisco).

-Cómo: La Ratio propone una «secuencia» de formación para el ministerio ordenado (tanto para seminaristas como para presbíteros). $Y$ da sus «razones», aunque no hay que esperar toda una teoría educativa.

-Formación: Dar forma, como si se tratara de la construcción de un edificio, sostenido por «cuatro pilares», como una estatua que hay que moldear, como un modelo al que hay que «con-figurarse».

-Discípulo misionero: Es la expresión que el Papa utiliza para todas las vocaciones en Evangelii gaudium. Todo cristiano es enviado para atender a los heridos en este campo de batalla que es nuestro mundo. (La imagen que define a la Iglesia para afrontar la deshumanización de nuestro mundo, que se nota sobre todo en la indiferencia ante los pobres, marginados e inmigrantes, es la de hospital).

-Preside el pueblo de Dios: Es la característica que define a los presbíteros, que no sólo son miembros del pueblo de Dios, sino que están colocados «al frente» de él (32, 90; citando PDV 16).

\section{La tradición}

Todo documento de la Iglesia trata situaciones nuevas desde una tradición. La Ratio no ha salido "de la nada», sino que es un paso más en un largo camino que se inicia en el Vaticano Il y llega hasta el Papa Francisco. Hay continuidad con la Ratio anterior de 1970 (actualizada en 1985, al ser revisado el Derecho canónico). Recoge enseñanzas de todos los papas del siglo pasado, sobre todo de Pastores dabo vobis de Juan Pablo II (1992), actualizando las cuatro dimensiones de formación: humana (93-100), espiritual (101-115), intelectual (116-118) y pastoral (119-124).

Ya el papa Benedicto XVI había sentido la necesidad de revisar la Ratio anterior, preocupado por la falta de profundidad en los estudios eclesiásticos, tanto en teología como en filosofía. El Papa proponía una vía agustiniana: una espiritualidad fuerte, explicada por la teología y fundamentada en la filosofía. 
El Papa Francisco insiste en que la dimensión misional pertenece al carácter de ser discípulos que tienen que curar a un mundo muy descentrado (cf. Evangelii gaudium), un mundo que está a punto del desastre (cf. Laudato si'). Además, la Ratio recoge citas de los numerosos discursos que el Papa Francisco ha dirigido a los seminaristas y al clero.

La Ratio sintetiza y ordena muchas normas emanadas de distintos dicasterios sobre problemas concretos.

En la base de todas estas consideraciones está el presbiterado y, por consiguiente, la formación de sus candidatos. Su fundamento se halla siempre en la Trinidad. Si la Iglesia tiene una estructura trinitaria, también el presbiterado y el proceso formativo que conduce a él han de estar fundamentados en la Trinidad (35):

-los presbíteros son «signo visible del amor misericordioso del Padre» en la Iglesia y en el mundo;

-al configurarse «en su ser con Cristo Cabeza, Pastor, Siervo y Esposo, participan de su único sacerdocio y de su misión salvífica, como colaboradores de los Obispos»;

-bajo la acción del Espíritu Santo, que suscita las diversas vocaciones en el pueblo de Dios (11).

Teniendo presente la actividad de la Trinidad, el presbítero ha de ser «el hombre de la comunión» (52).

La labor formativa tiene como punto de referencia a la Trinidad: «El seminarista está llamado a 'salir de sí mismo', para orientar sus pasos en Cristo, hacia el Padre y hacia los demás, abrazando la vocación al presbiterado, esforzándose por colaborar con el Espíritu Santo, realizando una síntesis interior, serena y creativa, entre fortaleza y debilidad» (29). «Estas características de la persona de Cristo ayudan a comprender mejor el sacerdocio ministerial en la Iglesia, inspirando y orientando bajo la acción del Espíritu, la formación de los seminaristas, para que, insertos en el misterio trinitario, alcancen la propia configuración con Cristo» (35).

De manera especial la formación espiritual ha de ser trinitaria, ya que «se orienta a alimentar y sostener la comunión con Dios y con los hermanos, en la amistad con Jesús Buen Pastor y en una actitud de docilidad al Espíritu» (101 más 102).

La Trinidad es además el principal agente de la formación al presbiterado, pues «modela a cada seminarista según el designio del Padre, por medio de la presencia de Cristo en su palabra, en los sacramentos y en los hermanos de la comunidad, a través de la multiforme acción del Espíritu Santo» (125). 
a) Dios Padre, origen de la vocación. «La vocación al presbiterado, de hecho, es un don de Dios a la Iglesia y al mundo» (3); es parte del designio amoroso de Dios (30), "que llama libremente a algunos al sacerdocio ministerial en una Iglesia particular», mientras que a otros los llama a ejercer el ministerio más allá de su diócesis (15). «Este don se expresa a lo largo del tiempo por mediación de la Iglesia, que llama y envía en nombre de Dios» (34).

La formación del seminarista ha de contar con la gracia de Dios (65), y consiste en salir de sí mismo hacia el Padre y hacia los demás entrando en un proceso que le lleve «a ser conscientemente libre para Dios y para los demás» (29). Por tanto, los seminaristas han de «adquirir la verdadera libertad y docilidad de los hijos de Dios, alcanzando el dominio espiritual que se requiere para conseguir una justa relación con el mundo y con los bienes terrenos» (111).

b) Jesús, el modelo configurador. Jesús es concebido desde la paternidad de Dios, como «Hijo predilecto del Padre, enviado como Pastor del pueblo de Dios» (68), «para realizar su designio de amor» (89). Siendo Hijo de Dios, ha asumido la condición de siervo (38). De esta manera, «Cristo revela que Dios es quien reúne, acompaña, atiende y cuida el propio rebaño» (37).

Los rasgos propios de Jesús, siguiendo Pastores dabo vobis, son Cabeza, Pastor, Siervo y Esposo (35):

-Cabeza. Es notable las pocas veces que la Ratio alude a Cristo Cabeza y menos todavía al presbítero como Cabeza, y las más de las veces lo hace en las notas. Conviene recordar que para Juan Pablo II es uno de los títulos claves tanto de Jesús como del presbítero, y que suele venir acompañado de los títulos Cabeza y Esposo.

-Pastor. Jesús es quien «da la vida en sacrifico... para reunir a las ovejas dispersas de la casa de Israel y conducirlas al redil del Reino de Dios... Cristo revela que Dios es quien reúne, acompaña, atiende y cuida el propio rebaño. Aparece así la imagen de un Dios-Pastor, que comparte nuestra vida, hasta tomar sobre sí nuestro sufrimiento y nuestra muerte» (37).

El presbítero ha salido de la comunidad cristiana para volver a ella, «para servirla y guiarla en calidad de pastor» (3 y además 32). «El presbítero, miembro del Pueblo santo de Dios, está llamado a cultivar su dinamismo misionero, ejercitando con humildad el deber pastoral de guía autorizado, maestro de la Palabra y ministro de los sacramentos, viviendo una fecunda paternidad espiritual» (33). 
La labor del seminario es formar discípulos, «enamorados del Maestro» (3), destinados a ser pastores (62). De ahí que tengan que alcanzar la «sólida madurez» que corresponde a un pastor (63). «Todo el proceso educativo de preparación al sacerdocio ministerial tiene como finalidad disponer a los seminaristas 'para comunicar la caridad de Cristo, buen Pastor'» (89, que cita PDV 57). Lo tiene que hacer poniéndose a la escucha de la Palabra de Dios (103) y desarrollando las virtudes del Buen Pastor, especialmente «humildad y misericordia para con todo el pueblo de Dios» (115).

"Ya que la finalidad del Seminario es la de preparar a los seminaristas para ser pastores a imagen de Cristo, la formación sacerdotal debe estar impregnada de un espíritu pastoral» (119), haciendo "a los futuros sacerdotes expertos en el arte del discernimiento pastoral». No en vano, aprendiendo a escuchar, «el Pastor llegará a ser capaz de hacer una lectura profunda de la realidad... La mirada del Buen Pastor, que busca, acompaña y guía a sus ovejas, lo conducirá a una visión prudente y compasiva; el pastor realizará su ministerio en un estilo de acogida serena y de acompañamiento vigilante de todas las situaciones» (120).

Este esfuerzo por configurarse con Cristo abarca toda la vida, pero de manera especial se enfatiza en la etapa de teología en la que el seminarista tiene delante de sí a "Cristo, Pastor y Siervo, para que, unido a él, pueda hacer de la propia vida un don de sí para los demás» (68). Esta etapa «facilita un arraigo gradual en la personalidad del Buen Pastor, que conoce a sus ovejas, entrega la vida por ellas y va en busca de las que están fuera del redil» (69).

La llamada a órdenes, «representa para él [seminarista] una invitación a proseguir su formación, en la configuración con Cristo Pastor, mediante el reconocimiento formal por parte de la Iglesia» (67). Pero lo que se hace en esta etapa de teología no es suficiente. Lo que ha empezado aquí, ha de seguir después de la ordenación, en la formación permanente del presbítero (70 y 71) para no caer en la tentación «de sentirse como un empleado de la comunidad o un funcionario de lo sagrado, sin corazón de pastor... 'solo quien se deja conformar con el Buen Pastor encuentra unidad, paz y fuerza en la obediencia del servicio'» (84, cita del Papa Francisco).

-Siervo. Es una faceta del Buen Pastor (68 y 70). Jesús asumió la condición de siervo hasta la muerte y lavó los pies de sus discípulos. De ahí que la referencia al siervo sufriente de Isaías ayude a entender la persona de Jesús (38), el cual «no vino para ser servido, sino para servir (Mt 20, 24-28)» (89). 
La vida del presbítero, que tiene que aprender el seminarista, consiste en «actuar desde la caridad pastoral que corresponde, al ser 'siervos de Cristo y administradores de los misterios de Dios' (1 Cor 4, 1)» (42), al ser "siervo y testigo de la Palabra en la Iglesia y en el mundo» (117).

-Esposo. Cristo se entrega a la Iglesia totalmente por amor; es como «la entrega originaria que es propia del esposo hacia la esposa» (PDV 22, citado en 39). Esa es la clase de entrega que «la ordenación presbiteral exige y posibilita... El presbítero es llamado a reproducir los sentimientos y las actitudes de Cristo en relación con la Iglesia, tiernamente amada mediante el ejercicio del ministerio; por tanto, se le pide 'ser capaz de amar a la gente con un corazón nuevo, grande y puro, con auténtica renuncia de sí mismo, con entrega total, continua y fiel, y a la vez con una especie de celo divino, con una ternura que incluso asuma los matices del cariño materno' (PDV 22)» (39).

Esta actitud es la que fundamenta «el celibato por el Reino de los cielos» como "signo de esta entrega total a Dios y al prójimo». "Arraigados en Cristo Esposo y totalmente consagrados al servicio del pueblo de Dios en el celibato, los presbíteros 'se unen más fácilmente [a Cristo] con un corazón no dividido... se dedican más libremente al servicio de Dios y de los hombres... y así se hacen más aptos para aceptar en Cristo una paternidad más amplia' [PO 16]» (110).

Esa es la clase de entrega que el futuro presbítero ha de aprender en el seminario, un «llamado a vivir la serenidad de fondo, humana y espiritual, que le permita, superada toda forma de protagonismo o dependencia afectiva, ser hombre de comunión, de misión y de diálogo, capaz de entregarse con generosidad y sacrificio a favor del pueblo de Dios, contemplando al Señor, que ofrece su vida por los demás» (41).

El proceso formativo a nivel de discipulado le ayudará a desarrollar tal madurez que, superando las diversas formas de individualismo, le permita «una generosa entrega a los demás» de sí mismo (63), bien fundamentada en los estudios de filosofía (158). En la etapa de configuración, el seminarista se dará cuenta de que su entrega sigue los pasos del Buen Pastor (69), en el marco de su propia diócesis, sin olvidarse de la Iglesia universal $(71,123)$. «La recepción del acolitado implica una participación más profunda en el misterio de Cristo que se entrega y está presente en la eucaristía, en la asamblea y en el hermano» (72).

Naturalmente eso no termina en el seminario, sino que ha de continuar en la formación permanente que le ayudará a desarrollar una disponibilidad «para la entrega total de sí a la Iglesia según el designio de Dios» (56). 
-A los títulos de Cabeza, Pastor, Siervo y Esposo habría que añadir el de Cristo Sumo Sacerdote. Siguiendo la pauta de la Carta a los Hebreos, el primer rasgo de Jesús, como Sumo Sacerdote, es la cercanía tanto a Dios como a los hombres «lleno de misericordia... habiéndose ofrecido a sí mismo...» según la voluntad del Padre (36). En cierto modo el sacerdocio está incluido en los títulos anteriores, pues «quien da la vida en sacrificio se presenta como el Buen Pastor» (37).

c) Espíritu Santo, la fuerza actuante. El Espíritu constituye a cada comunidad como «sacramento visible para la salvación del mundo» (31); la congrega para ser enviada a la misión y le permite colaborar en la formación de los sacerdotes $(91,125)$. Es el Espíritu Santo quien unge a todo creyente para que participe «activamente y según los carismas que le son propios, en la misión de la Iglesia» (32). Suscita asimismo las diversas vocaciones en el pueblo de Dios, entre ellas la llamada al presbiterado $(11,32)$.

Es también el Espíritu Santo quien inspira y orienta la formación de los seminaristas (35). Toda la formación consiste en abrirse «a la acción del Espíritu Santo, con la finalidad de formar un corazón sacerdotal» (55, más 63 y 69). Por tanto, el seminarista ha de ser «dócil» al Espíritu (68); el acompañamiento personal es un instrumento fundamental para fomentar esta docilidad $(45,46)$.

El Espíritu Santo está presente durante todo el proceso formativo (71). Desde el principio, sostiene con su fuerza a los adolescentes en su crecimiento vocacional (21); auxilia «a la persona a integrar» los aspectos de gracia y fragilidad «en un camino de fe y de progresiva armónica maduración de todos los componentes» (28). Por tanto, el seminarista ha de estar dispuesto a colaborar con el Espíritu Santo, para lograr una síntesis interior entre fortaleza y debilidad (29). El Espíritu Santo ayuda al seminarista a configurarse con Cristo de una manera gradual, que continúa más allá del seminario en la formación permanente (80), pues es el mismo Espíritu quien apoya la fraternidad sacramental entre los presbíteros (87).

Finalmente, el Espíritu Santo constituye al presbítero, mediante la imposición de las manos del obispo, en guía del Pueblo (34).

\section{Acompañamiento}

La Ratio insiste en que el seminarista es «sujeto» y actor de su formación (incluso le aplica la palabra «autodeterminarse», 96). «Se tenga presente que el seminarista en un primer momento -y el sacerdote despuéses el protagonista necesario e insustituible de su formación» (53, citando 
PDV 69). Se ha de ver como «misterio para sí mismo» con dos aspectos que debe aprender a integrar: «el conjunto de cualidades y riquezas, que son dones de gracia» y los «límites y fragilidades» que marcan su humanidad. Por tanto, «el tiempo de formación hacia el sacerdocio ministerial es un tiempo de prueba, de maduración y de discernimiento por parte del seminarista y de la institución formativa» (28).

-Por parte de los formadores. El acompañamiento personal es un instrumento indispensable de la formación que le ayuda al seminarista a ser dócil al Espíritu Santo $(45,46)$. Según esto, el seminarista ha de ser acompañado a lo largo de todo el proceso educativo (44-49) para facilitarle la integración de «todos los aspectos de la persona humana, educando en la escucha y el diálogo, para descubrir el verdadero significado de la obediencia y libertad interior», con el fin de que el seminarista se configure gradualmente con Cristo, bajo la acción del Espíritu Santo (46; además 72 y74).

-Por parte de toda la comunidad $(50-52,65)$. «El humus de la vocación al ministerio presbiteral es la comunidad, en cuanto que el seminarista proviene de ella, para ser, después de la ordenación, enviado a servirla. El seminarista primero, y el presbítero, después, tienen necesidad de un vínculo vital con la comunidad. Ella se presenta como un hilo conductor que armoniza y une las cuatro dimensiones formativas» (90).

El seminario es sólo una parte, aunque muy importante, en el proceso de la formación inicial. Ya pasaron los tiempos en que se veía al seminario como una institución total, que se bastaba a sí misma porque contenía todos los ingredientes necesarios para que un joven entrara como candidato y saliera ordenado a realizar el ministerio presbiteral, sin haber pisado «la ciudad». La Ratio limita significativamente la función del seminario poniéndole una etapa anterior (propedéutica) y otra posterior (diaconal). Por otra parte, coloca al seminario dentro del conjunto pastoral de la diócesis haciendo que no pueda funcionar sin la colaboración de la comunidad diocesana.

La formación de los candidatos a las órdenes está encomendada a una «comunidad formativa» de la que son parte el obispo, los formadores, los profesores, el personal administrativo, los trabajadores, las familias, las parroquias, las personas consagradas, el personal especializado y, sobre todo, los mismos seminaristas (139). También el presbiterio es «corresponsable» ya que ofrece "el ámbito de comunión fraterna en el ejercicio del ministerio ordenado» al que se prepara el seminarista. En este sentido también entran «las asociaciones, movimientos u otras instituciones eclesiales» (127). 
Dado que «el seminario, antes que un edificio, es una comunidad formativa», el obispo debe valorar cuidadosamente si cuenta con los elementos necesarios: un número suficiente de vocaciones, un cuadro de formadores, un cuerpo docente que ofrezca una propuesta intelectual de calidad y de que dispone de los medios económicos que lo convierten en un proyecto viable (188).

La Ratio apenas especifica lo que le corresponde a cada instancia comunitaria, excepto en el caso del obispo (ordinario de la diócesis), que tiene toda la responsabilidad en el fomento de vocaciones, la erección del seminario, el proceso educativo y el diseño del plan de formación. Para ello cuenta con la ayuda de la Congregación para el Clero (2) y de la Conferencia Episcopal de la nación, que ha de revisar y adaptar la Ratio fundamentalis, publicando una Ratio nationalis institutionis sacerdotalis (6-7), con la advertencia de que tal revisión no compete a cada obispo en particular (4).

Le toca al obispo, ayudado por el equipo de formadores del Seminario, elaborar un proyecto de «formación integral» o itinerario formativo, teniendo como «referencia» la Ratio fundamentalis y "aplicando» la normativa de la Ratio nationalis. Asumiendo «la visión pedagógica que la inspira», el obispo ha de buscar la manera práctica de implementarla «de acuerdo con la realidad y las exigencias de la Iglesia particular, teniendo en cuenta el origen cultural de los seminaristas, la pastoral de la diócesis y la propia «tradición formativa» (10), sin olvidarse de que debe encajar en el plan de conjunto de la pastoral diocesana (13).

Todo esto lo hace el obispo, no simplemente porque es el administrador de los asuntos diocesanos, sino porque él mismo es "el padre» de una familia, a la que pertenecen los presbíteros como «una fraternidad sacramental», para la que se preparan los candidatos a órdenes (51).

El obispo es el que elige al rector del seminario y a los miembros del equipo formador (128), a los directores espirituales que los seminaristas pueden elegir libremente de entre los sacerdotes designados por el obispo (107), que tendrá mucho cuidado en elegir «presbíteros competentes y experimentados para la dirección espiritual» (136). Los profesores también deben ser nombrados por el obispo (140).

El obispo es además responsable de aceptar a los candidatos al seminario. Con la ayuda del equipo formador, valorará las dotes humanas y morales y las disposiciones del candidato (189). La documentación médica y psicológica será conocida sólo «por el obispo y el rector del Seminario diocesano, y su divulgación estará regulada por las leyes civiles y 
eclesiásticas vigentes en cada país» (190). «El aspirante deberá dar a conocer al obispo y al rector del seminario eventuales problemáticas psicológicas anteriores, así como las medidas tomadas durante los periodos de terapia» (193, y 195; para los casos de homosexualidad, 200). Se debe consultar al obispo a la hora de expulsar a un seminarista (197) y de su vuelta al seminario (198).

El obispo debe estar al tanto de lo que se enseña en el seminario. La parte académica no debe ser afectada por las actividades pastorales durante la etapa del seminario. «Según el prudente juicio de los obispos, se introduzcan algunas experiencias de apostolado, durante todo el tiempo de formación, en los momentos y modos más oportunos, especialmente durante los días y periodos en que no hay clases» (124). Es conveniente que los seminaristas participen en los momentos más significativos del año litúrgico y de la vida diocesana, especialmente cuando el obispo celebre en la catedral, salvaguardando siempre las tareas formativas del seminario.

Es necesario que el obispo mantenga un diálogo abierto y confiando con los seminaristas, que los visite y esté al tanto de su progreso (como lo manda el Derecho canónico, 259, 2), pero teniendo mucho cuidado en no desacreditar al equipo formador (128).

Si los seminaristas son enviados a otros seminarios, «es responsabilidad del obispo diocesano garantizar su inserción en una verdadera comunidad formativa, evitando que un seminarista o un reducido grupo de candidatos, habite establemente en una residencia privada, donde sería imposible cultivar debidamente la vida espiritual y comunitaria» (188).

Finalmente, el obispo decide sobre la idoneidad del que debe ser ordenado (73), y su decisión ha de ser aceptada por el candidato con la ayuda de los formadores (77). De ahí la necesidad de «escrutinios» (203), basados en un informe del equipo formador al obispo (205). «El obispo tiene la responsabilidad canónica última y definitiva sobre la llamada a las sagradas órdenes... El obispo se abstenga de publicar la fecha de la ordenación diaconal y de permitir preparativos para la celebración del diaconado antes de que hayan sido concluidos con regularidad los estudios prescritos» (206). El obispo ha de tener en cuenta las normas jurídicas que aparecen en el Derecho canónico (207-210).

Después de la ordenación, «es competencia del obispo, ayudado por sus colaboradores, introducir a los nuevos presbíteros de las dinámicas propias de la formación permanente» (79). El obispo es también responsable de proveer un lugar adecuado a su desarrollo como presbítero (83), dirigiendo a algunos presbíteros a estudios de especialización (185). 


\section{El proceso de formación}

La formación recorre "un único camino discipular y misionero» (54). Por tanto abarca toda la vida. Ya queda atrás la idea de que uno recibía una formación completa en el seminario que le servía para la vida como presbítero. Estamos en continuo proceso de formación, hasta que nos morimos (54-56).

Dado que la «única formación» es «integral y progresiva, se distinguen la fase inicial y la permanente» (3).

Aquí nos ocupamos de la formación inicial, dejando la formación permanente para otra ocasión. Pero antes, quiero advertir que la Ratio pide que las diócesis establezcan un «centro de vocaciones» $(13,19)$, no sólo para las vocaciones diocesanas sino también para los institutos de vida consagrada, sociedades de vida apostólica y misioneros para otros países (15). Este programa ya es, por sí mismo, un primer paso formativo, aunque no entre dentro del proceso de formación formal. Es una especie de Pre-Propedéutica, pues ambos se dirigen al discernimiento.

La fase de formación inicial incluye tres etapas (57-58):

a) La Propedéutica. Esta etapa se presenta «con una identidad y una propuesta formativa específica» y es, por tanto, «necesaria y obligatoria» (3). Tiene como objetivo el «discernir la conveniencia de continuar la formación sacerdotal o emprender un camino de vida diverso», que se especifica en «asentar las bases sólidas para la vida espiritual y favorecer un mejor conocimiento de sí que permita el desarrollo personal» (59). Dura un año y debe tener su propio lugar, aparte del seminario, con programas específicos de estudio (155-157), donde se desarrollen las actitudes básicas para la vida comunitaria (dirección espiritual, liturgia de las horas, estudio del catecismo de la Iglesia) y también la incorporación afectiva a la diócesis (60). Al final de este proceso, se declara al participante candidato para el seminario.

b) El Seminario. Comprende la formación durante seis años de estudios eclesiásticos. Para recalcar que se trata primariamente de formación, se definen estos años como etapa de discipulado (equivalente a la filosofía) y etapa de configuración (equivalente a la teología).

-Discipulado: Dura dos años (61-67) con estudios centrados en la filosofía (158-164). El objetivo principal es formar el carácter del seminarista, desarrollando las virtudes humanas e introduciéndolo en un hábito de oración tanto personal como comunitaria. Al final de este proceso se le considera candidato para órdenes. 
-Configuración: Se intenta que el seminarista adquiera una forma de acuerdo a Cristo Siervo y Pastor. Dura cuatro años (68-73) con estudios centrados en la teología (165-175) atendiendo a la práctica pastoral (176184). En esta etapa se insiste en el desarrollo de las virtudes teologales y de los consejos evangélicos, en su identidad diocesana, poniéndose al servicio de la Palabra como lector y del altar como acólito (aunque se pide que ejerzan el ministerio más allá de la liturgia «en la catequesis, la evangelización y el servicio al prójimo», 72). Esta etapa termina con la ordenación al diaconado.

c) La Parroquia. Es el «tiempo que transcurre entre la conclusión de la formación en el seminario y la ordenación presbiteral, a fin de favorecer en el candidato una adecuada preparación previa a dicha ordenación» (3). «La finalidad de esta etapa es doble: se trata, por un lado, de insertarse en la vida pastoral, mediante una gradual asunción de responsabilidades, con espíritu de servicio; por otro lado, de esforzarse en adquirir una adecuada preparación, recibiendo un acompañamiento específico con vistas a la recepción del presbiterado» (74). El seminarista, una vez ordenado diácono, deja el seminario y se inserta en una parroquia por el tiempo determinado por el Derecho canónico o más, si el obispo lo considera oportuno (74-79). En este ambiente y bajo la responsabilidad de un presbítero designado por el obispo, que debe ser «consciente de la responsabilidad formativa que recibe y lo acompañe en su gradual inserción» (75), el diácono se va haciendo cargo de una manera gradual de las responsabilidades exigidas por el ministerio y se prepara para la ordenación presbiteral, que se da cuando el obispo lo crea conveniente.

\section{REFLEXIÓN DESDE LA TRADICIÓN LOCAL}

La Ratio reconoce la existencia de una «tradición formativa» propia en la Iglesia local $(10,154)$ y también de una «tradición pastoral» (123) que el obispo ha de tener en cuenta cuando elabore su plan de formación de acuerdo al plan pastoral de conjunto de la diócesis (13).

Este tema abre otro mayor, que es el de la recepción de los documentos de la Iglesia universal por parte de las Iglesias particulares, del que ahora no nos podemos ocupar. En todo caso, no se puede considerar la Ratio nationalis o la elaboración del plan episcopal como algo equivalente a la recepción, ya que la misma Ratio fundamentalis pide que la comunidad sea agente de la formación del candidato al presbiterado. ¿Cómo va a ser agente en un proceso que no conoce o que, tal vez, ni siquiera 
comparte? La Ratio no debe caer en manos de una élite, que termine archivándola en un lugar seguro.

La Ratio no responde a todos los problemas ni tampoco es un libro de texto de pedagogía. La Ratio viene en ayuda de una "tradición» ya existente. Debe de haber un acoplamiento entre las dos, para que la diócesis disponga de un medio para formar a los pastores; en concreto, la clase de pastores que necesita para atender al pueblo de Dios en el lugar específico de una Iglesia particular.

Las normas de la Ratio vigen tanto para seminarios diocesanos como religiosos. Las conferencias nacionales han de hacer sus propias adaptaciones. Y cada obispo las recibe elaborando su propio plan.

\section{Presbitero / Sacerdote}

La Ratio usa las palabras "presbítero» y «sacerdote» como sinónimos. Habla tanto de la «vocación presbiteral» como de la «institución sacerdotal». «Presbítero» parece ser la designación más antigua en la Iglesia (ya que el Nuevo Testamento aplica «sacerdote» sólo a Jesús, sumo sacerdote, y al pueblo santo, que es «sacerdotal»). "Sacerdote» aplicado a individuos que ejercen un ministerio en la Iglesia aparece siglos más tarde. También el Vaticano II prefiere la palabra «presbítero», que la usa de una manera consistente, aunque no exclusiva, a lo largo de los documentos conciliares.

El presbítero tiene varias dimensiones, mientras que el sacerdote se concentra en la liturgia y su lugar propio es dentro del templo. Sin querer (¿० tal vez «a propósito»?) se reduce el presbiterado a una sola de sus dimensiones. Me parece que esta reducción subyace en la Ratio, a pesar de su insistencia en la misión. El presbítero acaba siendo «guía autorizado, maestro de la Palabra y ministro de los sacramentos viviendo una paternidad espiritual» (33). Es decir, celebrante y, tal vez, catequista y director espiritual.

\section{Interior/Exterior}

Seguimos con el vocabulario. A pesar de las abundantes citas del Papa Francisco, no aparecen en la Ratio palabras que él usa con cierta frecuencia: guerra, pelea, batalla, lucha. Incluso la palabra «violencia» sólo aparece en el apartado de protección de menores («posible abuso o violencia», 202) y otra vez como uno de los "desafíos que emergen de la cultura secular» (175), como si el seminarista viviera fuera de esta cultura secular. 
¿No es cierto que los candidatos vienen al seminario muy «heridos», que han experimentado "violencia» en su propia carne y en la de sus vecinos y que ven «el mundo» como un lugar peligroso? Más aún, ¿no se encuentra el seminarista en una guerra constante consigo mismo y con el medio ambiente durante los años de formación?

Como no se habla de violencia, tampoco se habla de paz, a pesar de la riqueza de matices que tiene esta palabra en san Agustín y en toda la mística católica. Dos veces aparece la palabra «paz» en la Ratio. Una es una cita del Papa Francisco que no afecta al texto (84), y otra entre los valores que se han de tratar en «un número determinado y suficiente de lecciones [que] se debe reservar a la enseñanza de la Doctrina Social de la Iglesia» (172). ¿Será el candidato al presbiterado, «un hombre de paz»?, ¿podrá ser enviado como «mensajero de paz» para guiar al pueblo de Dios en una «misión de paz»?

La Ratio puede tomar esa postura porque se concentra en la «interioridad», como si fuera una dimensión independiente de lo exterior. Habla de «la llamada interior del Señor» (2016), de la «libertad interior» de la respuesta (18), de la «síntesis interior» en colaboración con el Espíritu Santo (29), de que los fundamentos de la formación están basados en la interioridad (41-43), que el acompañamiento se ha de hacer respetando «la libertad interior» (46), que la formación permanente ha de promover la actitud interior del presbítero $(56,80)$. Se espera que el seminarista alcance un alto nivel de madurez interior al final de los estudios filosóficos (67), hasta que llegue a integrar todo internamente (92). Ha de saber interiorizar los textos bíblicos (102) y desarrollar una disciplina interior (106) y una obediencia interior (109). Ha de hacer que «la libertad interior» de su apostolado se traduzca en servicio (119), interiorizando un estilo de vida (136). Todo el proceso formativo ha de estar dirigido a promover la «libertad interior» para una vida ministerial (148). Los formadores deben desarrollar «una disposición interior» (152). Los seminaristas han de conocer la «interioridad del ser humano» (163). En particular, deben desarrollar «la actitud correcta interior» hacia el pueblo judío (166).

Desde los primeros días del Concilio Vaticano II se alzaron diversas voces avisando sobre el peligro de reducir las reformas a un cambio de cosas, sin una conversión interior. Este «peligro» no ha aminorado con el paso del tiempo, sino que ha ido en aumento. ¿No se estará matando la «novedad» del propio concilio por miedo a quedarse en «apariencias»? ¿no se estará buscando una excusa para evitar un compromiso social y «quedarse en casa»? 
La distinción del hombre en cuerpo y alma de la filosofía griega, que mantiene la filosofía escolástica, se convirtió en división entre interioridad (espiritualidad mental) y exterioridad (materia extensa) con Descartes, y desde entonces ha primado en la vida religiosa. Tanta insistencia en la interioridad ¿no llevará a una esquizofrenia personal y a un divorcio con la comunidad? Esta puede ser una puerta abierta a una espiritualidad elitista, que el Papa Francisco tanto critica.

\section{Práctica / Pastoral}

La Ratio dedica todo el capítulo VII a los estudios de filosofía y teología, a los que se añade un apartado sobre «materias ministeriales», que prácticamente se deja en manos de la Ratio nationalis $(176,184)$, aunque se recalcan los puntos centrales que ha de tratar: el arte de celebrar y la homilía (177), el ministerio de la confesión (178), la religiosidad popular (179), la administración de bienes (180), el arte sacro (181), los medios de comunicación social (182) y aprendizaje de una lengua moderna (183). ¿Es esto todo lo que hace falta para guiar al pueblo de Dios en tiempos de «una crisis planetaria» (172)?

La formación, de acuerdo a la Ratio, no es únicamente un proceso, sino una «secuencia»: primero se edifica la humanidad, la espiritualidad y la academia, a nivel de filosofía; después se afianza conformándolo a Cristo en la teología, para por último practicar todo lo que se ha aprendido. La pastoral aparece al final, aunque se aconseja realizar algunas «experiencias» durante el tiempo del seminario, con la advertencia repetida de que no interrumpan los estudios. Es entonces cuando se supone que se produce la síntesis; carácter humano, discipulado y conocimiento se unifican en la acción.

¿Hay que esperar al final para que haya una síntesis? El proceso educativo comienza con una síntesis, tal vez muy provisional, pero es la que trae el seminarista de su parroquia (da la impresión de que la Ratio considera que los candidatos vienen al seminario con una tabula rasa, sin previas experiencias religiosas en sus parroquias). Según progresa, el seminarista construye nuevas síntesis. En parte, porque el compromiso pastoral le obliga a repensar no sólo como aplicar doctrinas, sino también cómo se relaciona con los demás, y cómo va construyendo su identidad como ministro. Son síntesis provisionales, pero la síntesis que se hace al final del proceso formativo, cuando uno ha concluido en el seminario y ha sido ordenado diácono, también es provisional, puesto que la formación 
continúa y el ordenado se ve obligado a hacer nuevas síntesis durante toda su vida de ministerio presbiteral.

Es decir, la labor pastoral es formativa; no es simplemente una práctica o una aplicación de doctrinas que se han adquirido con anterioridad. Además, el ministerio pastoral sigue siendo formativo después de la ordenación sacerdotal.

Por eso me parece problemática la última etapa diaconal porque, según la Ratio, es un tiempo para prepararse a la ordenación presbiteral y una primera toma de contacto con las responsabilidades pastorales. La Ratio parece suponer que se pasa del diaconado al presbiterado casi automáticamente desde el punto de vista formativo, hasta el punto de que se la coloca sin ninguna relación con el seminario.

\section{Diocesaneidad / Universalidad}

La Iglesia local constituye el contexto imprescindible del proceso formativo. Aquí es donde se lleva a cabo la formación para el presbiterado (126). Por tanto, desde el principio, «es importante que en la propuesta formativa se acentúe el valor de la comunión con el propio obispo, con el presbiterio y con la Iglesia particular» (60). Desde la etapa propedéutica hay que desarrollar la diocesaneidad, sobre todo cuando muchos candidatos proceden de movimientos o grupos de espiritualidad peculiar. El seminarista ha de «adaptar el propio modo de sentir y de actuar, en comunión con el obispo y los hermanos sacerdotes, por el bien de una porción del pueblo de Dios» (71; además 88,129$)$. No se trata sólo de aceptar una realidad, la del contexto formativo, sino de desarrollar un amor sincero por la propia diócesis y su obispo $(71,123)$. Lo hace el candidato estudiando la realidad diocesana y su historia, incluyendo los santos propios de la región (157), hasta llegar a la etapa de configuración donde se han de formar en la espiritualidad del presbítero diocesano, sabiendo apreciar la «tradición pastoral» de la Iglesia local (123). Por eso los seminaristas han de asistir a las celebraciones litúrgicas presididas por el obispo en la catedral, pues «manifiestan el misterio de la Iglesia y hacen visible la unidad del pueblo de Dios» (128).

Por tanto, la diocesaneidad exige: comunión y sintonía profunda con el obispo diocesano (129), además de espíritu de comunión en la «fraternidad sacramental» (51; lugar de la formación permanente, 81-87), que incluye la vida común que «ayuda también a sostener el equilibrio afectivo y espiritual de quienes participan en ella y promueve la comunión con el obispo» (88). 
El presbítero se prepara para servir a una Iglesia particular con una entrega desinteresada. «La vinculación con la Iglesia local concierne específicamente al clero secular, pero incluye indistintamente a todos los presbíteros que ejercen el ministerio en ella» (71). De ahí que los seminaristas tengan que ser «formados en la estima de los diversos carismas presentes en la comunidad diocesana; el presbítero, efectivamente, tiene el deber de animar la diversidad de los carismas dentro de la Iglesia» (150).

Pero no hay que olvidar que la ordenación presbiteral implica la entrega a la Iglesia universal, a la que tiene que estar dispuesto a servir $(123,126)$; el presbítero debe de estar dispuesto a ir a otras diócesis y ha de promover toda clase de vocaciones, incluidas a la vida religiosa y misiones (15).

Precisamente por este carácter diocesano, el seminario ha de actuar en sintonía y en estrecho contacto con otras instituciones diocesanas, en especial a la hora de promover la formación pastoral (124). Así, el seminario deja de ser una institución total, autosuficiente, aislada, donde se dan todos los elementos necesarios para la educación de sus miembros, sin tener que salir fuera de su recinto (incluso físicamente).

La diocesaneidad constituye a todos los católicos en «comunidad educativa», corresponsables de la formación de los candidatos al presbiterado $(127,150,151)$. El principio está bien establecido en la Ratio, pero la manera en que estas instancias inciden en la formación del seminarista no están especificadas, excepto en el caso del obispo. Creo que si se viera la pastoral (o compromiso apostólico) desde un punto de vista formativo habría más claridad en cómo la comunidad participa en la formación. Ya que la comunidad, cuando se hace un trabajo pastoral prolongado en la parroquia, no sólo ofrece su colaboración, sino también su sabiduría al ver cómo actúa el seminarista en su aprendizaje hacia el presbiterado.

\section{Conclusión}

La Ratio ofrece una buena propuesta para desarrollar la interioridad del seminarista, pero tal propuesta debe ser completada por la «tradición formativa» local sobre temas fundamentales que la Ratio no trata. No creo que el proceso formativo que propone la Ratio sea suficiente para pensar que el futuro presbítero esté preparado para guiar al pueblo de Dios en el mundo en que vivimos. Las Conferencias Episcopales han de ir más allá de una simple adaptación de las normas de la Ratio si queremos que el proceso formativo sirva para tener ministros que respondan a la situación en que se encuentra la Iglesia en cada país. 


\section{En EL SEMINARIO de SAN BERNARDINo, En CALIFORNIA}

El proceso de formación de la diócesis de San Bernardino abarca dos fases. La del discipulado (filosofía), que se hace en la Casa de Formación Junípero Serra (Serra House), y la de la configuración (teología), que se realiza en el seminario de la Asunción en San Antonio, Texas, y en el de San Juan, Camarillo, California.

El Handbook (el libro de normas para los seminaristas) describe así el propósito de Serra House: «El Programa de formación de Serra House acompaña a jóvenes al inicio de su proceso vocacional hacia el sacerdocio ordenado en la Iglesia Católica y su inserción en la diócesis de San Bernardino. Los principios que guían a los seminaristas a nivel de college [filosofía] son:

a) La meta del Seminario College es la formación de discípulos misioneros en vista a su preparación para ser candidatos al ministerio sacerdotal como pastores para el pueblo de Dios a nivel de teología.

b) El Seminario College se centra en la madurez humana. Se espera que el seminarista alcance un cierto nivel de madurez en su desarrollo humano, en su vida espiritual, en su conciencia vocacional, en su experiencia pastoral y en su labor académica. Esta [los estudios] no debe ser el criterio definitivo para permitir que los seminaristas pasen al nivel de teología.

c) La formación debe hacerse en compañía del pueblo, no solamente formando una comunidad educativa en Serra House, sino en comunión con todo el pueblo de Dios en la diócesis de San Bernardino, especialmente con los que viven en sus propias parroquias».

Como puede verse, el programa de Serra House está en línea con las preocupaciones de la Ratio. Sin embargo, hay normas en la Ratio que pueden implicar cambios en la manera como la diócesis tiene planteada la formación al presbiterado.

\section{A nivel propedéutico}

Compartimos con la Ratio la necesidad de un periodo de preparación antes de entrar en el seminario. Hemos notado que:

-algunos jóvenes vienen al seminario con una formación religiosa y académica deficiente, que no les permite desenvolverse bien en el nivel universitario (college), aunque tengan los debidos diplomas;

-algunos jóvenes vienen al seminario con una idea de la vocación sacerdotal poco definida. Tienen buenas intenciones de servir al pueblo de Dios y conocen a algunos presbíteros ejemplares, pero no son capaces de ar- 
ticular una explicación de su vocación al presbiterado. Algunos de ellos han tenido fuertes experiencias de conversión o pertenecen a grupos de jóvenes muy activos, pero con poco discernimiento vocacional;

-algunos jóvenes extranjeros no hablan inglés o tienen un inglés «de la calle».

Esta es una realidad a la que tenemos que encontrar una mejor solución de lo que ahora hacemos.

Pero ¿vienen todos los candidatos en estas condiciones?

-Hay jóvenes que vienen de otros seminarios u órdenes religiosas que, por ciertas circunstancias (por ejemplo, el desplazamiento de las familias), se afincan en nuestra diócesis y piden entrar en el seminario.

-Hay adultos, con carreras o títulos académicos, que solicitan iniciar su formación hacia el presbiterado después de años de ejercer una profesión.

-Hay candidatos insertos ya en ministerios parroquiales y que han pasado por los cursos de formación que exige la diócesis para lectores, catequistas, etc.

Todas estas personas no caben en un mismo programa propedéutico. $\mathrm{Ni}$ tampoco los números lo permiten, ya que estamos hablando de unas diez personas nuevas cada año distribuidas en los apartados descritos arriba. Un periodo de preparación antes de entrar en el seminario parece claro, pero que todos los que aplican tengan que entrar por un mismo programa propedéutico no parece tan claro.

Dado que la diócesis distingue entre Oficina de Vocaciones (que hace las veces de un Centro de Vocaciones) y Casa de Formación, y de que el propedéutico va dirigido al "discernimiento» y se hace aparte del College, surge la pregunta de a quién corresponde dirigir este programa. El asunto es más complicado de lo que parece, porque parte de los estudios que la Ratio propone para el propedéutico forman parte de los estudios requeridos en College. En consecuencia, la separación radical que propone la Ratio es cuestionable desde este punto de vista. Habrá que esperar a la adaptación de la Conferencia Nacional.

\section{A nivel de discipulado (filosofía, college)}

No entro en la cuestión del «sexenio» de los estudios eclesiásticos que la Ratio propone, siguiendo el Derecho canónico, porque ya este asunto está resuelto en las anteriores Ratio nationalis de Estados Unidos (Program of Priestly Formation, PPF). 
Cada vez vemos más claro que el seminario hace muchas cosas bien, pero que no puede ofrecer todo lo que hace falta para una buena formación al presbiterado. La diócesis tiene que poner su parte. Estamos en esta búsqueda de hallar los medios y ya hemos encontrado algunas áreas de colaboración, por medio del trabajo apostólico de los seminaristas, el internship, la participación en eventos diocesanos, servir en las celebraciones presididas por el obispo, comidas en su casa y las reuniones de seminaristas, en las que participan las oficinas diocesanas para poner a los seminaristas al día de lo que pasa en la diócesis.

La Ratio permite la colaboración con otras entidades, como lo estamos haciendo en San Bernardino. Según la Ratio, el estudio de la filosofía es necesario para que los seminaristas tengan conceptos «metafísicos» que les ayuden a estructurar la teología y para que sepan cómo contrarrestar ideas «modernas» sobre Dios, el hombre y el mundo. Se habla también de estudiar la historia de la filosofía para conocer los orígenes de nuestras ideas (lo mismo se dice de la teología) como si se tratase de un catálogo de opiniones abstractas que nada tienen que ver con el desarrollo actual de la persona del seminarista. Así se pierde el sentido de la filosofía como "sabiduría» (a pesar de varias citas que utilizan la palabra) que ayuda a la persona a cimentar su relación con Dios, el universo y los demás. La filosofía tiene valor no sólo de cara a la teología, sino también como instrumento de crecimiento del propio estudiante. Es un medio para afianzar su dimensión humana.

A pesar de que el énfasis recae sobre la formación, los estudios siguen estructurando la vida del seminario. A ella se le dedica todo el capítulo VII (Organización de los Estudios de filosofía y teología, a los que se les añade otras «materias ministeriales»). Sin embargo, no hay un capítulo paralelo dedicado a la formación, aunque se habla de las evaluaciones al término de cada etapa (58). Por ejemplo, el PPF (quinta edición, 2006) habla de thresholds (mínimos) a nivel humano, espiritual, intelectual, empatía, comunicación y sexualidad antes de entrar en el seminario, y después especifica algunos de ellos para cada etapa del seminario. EI PPF ofrece un catálogo de actitudes que el seminarista debe desarrollar en su etapa formativa. La Ratio pide a las Conferencias Nacionales que hagan una declaración de la implementación detallada de los estudios (7) y no se les exige nada parecido sobre lo que se espera en el desarrollo humano y vocacional. Ni tampoco se establecen mínimos en el compromiso apostólico que se deben exigir a los seminaristas en cada etapa de su formación. 


\section{A nivel de configuración (teología)}

Si la lógica de la Ratio se mantiene, tendría que desaparecer la etapa pastoral (internship) que en Estados Unidos se acostumbra hacer después del segundo o del tercer año de teología, pues el equivalente a la etapa pastoral sería el diaconado, que se haría una vez terminados los estudios de teología.

En la práctica actual, el internship funciona como un último intento de discernimiento (si se hace después del segundo año de teología) o de un instrumento de formación del seminarista como agente pastoral (si se hace después del tercer año). Todo esto desaparecería para que el diácono fuera tomando responsabilidades parroquiales hasta que fuera ordenado presbítero después de haber dejado el seminario. Me imagino que muchos obispos van a tener problemas con este planteamiento, pues el año de pastoral en la parroquia revela muchas actitudes del candidato que en el seminario no salen a flote. Además, es conveniente que el seminarista tenga la oportunidad de corregirlas de vuelta en el seminario, pues el obispo quiere estar seguro de que así se haga antes de ser ordenado diácono.

El internship es la gran oportunidad que tiene la parroquia (párroco y laicos) para ser agente en el proceso formativo del seminarista. Tal como se realiza en Estados Unidos, se asigna el acompañamiento del seminarista a un grupo de laicos, bajo la orientación y dirección de un supervisor enviado por el seminario. Este comité de laicos le comunica claramente al seminarista cómo influye en la gente y sus posibles virtudes y defectos en su relación con los demás. Los ministros y los empleados de la parroquia también ofrecen su versión de cómo se comporta el seminarista cuando actúa como ministro en la parroquia. Sobre todo, es la gran oportunidad del párroco para ver al seminarista como colaborador pastoral suyo, ya que tienen que vivir juntos, orar juntos y revisar juntos la vida y la pastoral en una reunión semanal. El seminarista empieza a descubrir la «fraternidad sacramental» del presbiterado, pues ha de acompañar al párroco a las sesiones de formación que la diócesis establece para todos los presbíteros. Todo esto se hace con la asistencia del Director de los seminaristas de la diócesis. Este es un proceso muy valorado por los obispos.

\section{Diaconado en la parroquia}

«Después de la ordenación diaconal, la idoneidad para el presbiterado se presume» (209). Me imagino que muchos obispos van a tener problemas con esta presunción, sobre todo si el seminarista no ha vivido por un 
tiempo largo en una parroquia antes de ser ordenado al diaconado ni ha participado en otras acciones pastorales.

Tal como está descrita esta etapa en la Ratio deja abiertas muchas preguntas, incluso desde el punto de vista jurídico. Pues si esta etapa no tiene que ver nada con el seminario, sino que se hace en una parroquia, ¿quién recomienda al diácono para ordenes (se supone que esto le compete al rector del seminario)?

\section{REFLEXIONES FINALES}

La formación de los candidatos a órdenes es una preocupación constante en la Iglesia. Las guías generales, tanto de la Iglesia universal como de las Conferencias Nacionales, son renovadas con cierta frecuencia. La última Ratio recoge muchas de las normas que se han ido dando durante los últimos años y las ha puesto en un todo coherente. Así define el «deber pastoral» del presbítero como «guía autorizado, maestro de la Palabra y ministro de los sacramentos» (33, citando el título de un documento de la Congregación del Clero del 19 de marzo de 1999). Parece que a la Ratio le preocupa preparar buenos predicadores, celebrantes y directores espirituales.

La conciencia de que la formación abarca toda la vida va tomando cuerpo con la distinción de etapa inicial y formación permanente, que juntas constituyen un todo. La Ratio recorta el papel que juega el seminario en el proceso de formación. Primero, se coloca al seminario dentro de la fase «inicial» de formación y después se pone la etapa propedéutica al principio y la etapa parroquial al final.

La Ratio insiste en la comunidad formativa, que ve muy claro en términos teóricos, pero que ofrece pocas guías de cómo lo han de hacer los distintos componentes de la comunidad (excepto en el caso del obispo, para quien la Ratio ofrece una amplia lista de responsabilidades). Se echa en falta una referencia al pueblo de Dios, que no sólo acompaña, sino que pide la ordenación de candidatos, porque los conoce, ora por ellos $y$, por eso, los presenta, como dicen los praenotanda del actual rito de ordenación.

La Ratio no es un documento de teología sobre el presbiterado, pero "hace» teología cuando fomenta la "escalera de honores»: candidato, lector, acólito, diácono, presbítero. Si el diaconado es una vocación específica y valiosa en sí misma, ¿podemos seguir tratándolo como un paso previo al presbiterado? ¿No estaremos ordenando a personas que no han 
sido llamadas al diaconado? (Creo que esta Ratio ya es consciente del problema, puesto que recomienda que no haya celebraciones donde se ordenen a la vez diáconos y presbíteros, 78).

Hay muchos puntos que las Conferencias Nacionales tendrán que vaIorar; por ejemplo, el equilibrio entre interioridad y exterioridad, la reducción de la pastoral a "experiencias» sueltas y, para mí, sobre todo, la poca insistencia en preparar ministros para dirigir al pueblo de Dios en un mundo en crisis.

El Papa Francisco ha propuesto la metáfora de la Iglesia como un hospital de campaña en medio de un campo de batalla, idea que me parece que fundamenta la Ratio. ¿Es esto suficiente? Hay que tener en cuenta que el Papa Francisco ha escrito otra carta sobre la condición del mundo, que marcha hacia su propia destrucción si no cambia de dirección (Laudato si'). Es la imagen de «la casa que se nos viene abajo» porque no la estamos cuidando bien. La indiferencia hacia los pobres nos convierte en explotadores del mundo en que vivimos. Por tanto se requiere que los presbíteros sepan dirigir al pueblo de Dios en esta tarea de cuidar de «nuestra casa». ¿No debería el ministro ordenado estar preparado para dirigir las comunidades que preside para que el pueblo de Dios colabore con otros en «la crisis presente»? 